\title{
Erratum to: Analysis of the Reactive Element Effect on the Oxidation of Ceria Doped Nickel
}

\author{
R. W. Jackson · J. P. Leonard • L. Niewolak • \\ W. J. Quadakkers • R. Murray • S. Romani • \\ G. J. Tatlock $\cdot$ F. S. Pettit $\cdot$ G. H. Meier
}

Published online: 13 September 2013

(C) Springer Science+Business Media New York 2013

Erratum to: Oxid Met (2012) 78:197-210

DOI 10.1007/s11085-012-9300-z

The following errors were inadvertently overlooked in the original publication of the article and it has been corrected with this erratum

- Unfortunately, the Fig. 8 in the originally published article is actually the same as Fig. 6, i.e., Fig. 6a and b. Therefore, the correct version of Fig. 8 is presented below.

The online version of the original article can be found under doi:10.1007/s11085-012-9300-z.

R. W. Jackson · J. P. Leonard · F. S. Pettit · G. H. Meier $(\bowtie)$

Department of Mechanical Engineering and Materials Science, University of Pittsburgh,

Pittsburgh, PA, USA

e-mail: ghmeier@pitt.edu

L. Niewolak · W. J. Quadakkers

Forschungszentrum Jülich, IEF-2, 52428 Jülich, Germany

R. Murray · S. Romani · G. J. Tatlock

Centre for Materials and Structures, School of Engineering, University of Liverpool, Liverpool, UK 

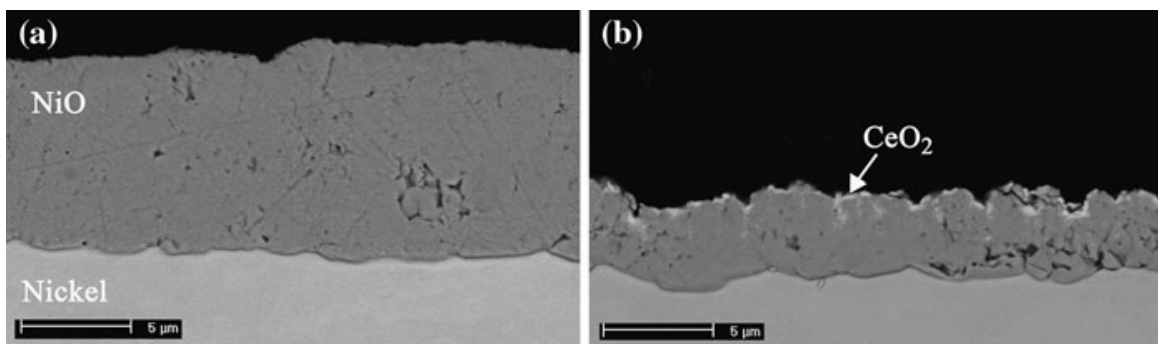

Fig. 8 Cross-sections of nickel which was oxidized for $15 \mathrm{~min}$ at $800^{\circ} \mathrm{C}$ in air and then a re-exposed for $50 \mathrm{~h}$, and $\mathbf{b}$ a separate specimen which was coated with $\mathrm{CeO}_{2}$ following pre-oxidation and then reexposed for $50 \mathrm{~h}$

This figure is important in making a key point of the paper that the reactive element effect obtains even when the reactive element, in this case $\mathrm{Ce}$, has no access to the metal/oxide interface.

- Secondly, Fig. 10 is duplicated, i.e. there should only be one image in Fig. 10. 